\title{
Frequency Tuning of the Efferent Effect on Cochlear Gain in Humans
}

\author{
Vit Drga, Christopher J. Plack and Ifat Yasin
}

\begin{abstract}
Cochlear gain reduction via efferent feedback from the medial olivocochlear bundle is frequency specific (Guinan, Curr Opin Otolaryngol Head Neck Surg 18:447-453, 2010). The present study with humans used the Fixed Duration Masking Curve psychoacoustical method (Yasin et al., J Acoust Soc Am 133:41454155, 2013a; Yasin et al., Basic aspects of hearing: physiology and perception, pp 39-46, 2013b; Yasin et al., J Neurosci 34:15319-15326, 2014) to estimate the frequency specificity of the efferent effect at the cochlear level. The combined duration of the masker-plus-signal stimulus was $25 \mathrm{~ms}$, within the efferent onset delay of about 31-43 ms (James et al., Clin Otolaryngol 27:106-112, 2002). Masker level ( 4.0 or $1.8 \mathrm{kHz}$ ) at threshold was obtained for a $4-\mathrm{kHz}$ signal in the absence or presence of an ipsilateral $60 \mathrm{~dB}$ SPL, 160-ms precursor (200-Hz bandwidth) centred at frequencies between 2.5 and $5.5 \mathrm{kHz}$. Efferent-mediated cochlear gain reduction was greatest for precursors with frequencies the same as, or close to that of, the signal (gain was reduced by about $20 \mathrm{~dB}$ ), and least for precursors with frequencies well removed from that of the signal (gain remained at around $40 \mathrm{~dB}$ ). The tuning of the efferent effect filter (tuning extending $0.5-0.7$ octaves above and below the signal frequency) is within the range obtained in humans using otoacoustic emissions (Lilaonitkul and Guinan, J Assoc Res Otolaryngol 10:459-470, 2009; Zhao and Dhar, J Neurophysiol 108:25-30, 2012). The $10 \mathrm{~dB}$ bandwidth of the efferenteffect filter at $4000 \mathrm{~Hz}$ was about $1300 \mathrm{~Hz}\left(\mathrm{Q}_{10}\right.$ of 3.1). The FDMC method can be used to provide an unbiased measure of the bandwidth of the efferent effect filter using ipsilateral efferent stimulation.
\end{abstract}

Keywords Auditory · Fixed-duration masking curves · Forward masking • Compression $\cdot$ Gain $\cdot$ Efferent $\cdot$ Precursor $\cdot$ Frequency-range

\footnotetext{
V. Drga $(\bowtie) \cdot$ I. Yasin

Ear Institute, University College London (UCL), 332 Grays Inn Road, WC1X 8EE London, UK e-mail:v.drga@ucl.ac.uk

I. Yasin

e-mail: i.yasin@ucl.ac.uk

C. J. Plack

School of Psychological Sciences, The University of Manchester, M13 9PL Manchester, UK e-mail: Chris.Plack@manchester.ac.uk

(C) The Author(s) 2016

P. van Dijk et al. (eds.), Physiology, Psychoacoustics and Cognition in Normal and Impaired Hearing, Advances in Experimental Medicine and Biology 894, DOI 10.1007/978-3-319-25474-6 50
} 


\section{Introduction}

In addition to ascending (afferent) neural pathways, the mammalian auditory system contains descending (efferent) neural projections from higher to lower levels of the auditory system [ipsilateral and contralateral efferent systems of cat (Liberman 1988; Huffman and Henson 1990) and human (Guinan 2006)]. The mammalian auditory system includes a brainstem-mediated efferent pathway from the superior olivary complex by way of the medial olivocochlear bundle (MOCB) which reduces the cochlear gain applied over time to the basilar membrane (BM) response to sound [electrical stimulation of the olivocochlear bundle (OCB) in guinea-pigs (Murugasu and Russell 1996)]. The human MOCB response (as measured using otoacoustic emissions: OAEs) has an onset delay of between 25 and $40 \mathrm{~ms}$ and rise and decay time constants in the region of 280 and $160 \mathrm{~ms}$, respectively (Backus and Guinan 2006). Recordings from guinea pigs show the greatest reduction in BM vibration due to efferent stimulation when the stimulating tone is close to or above the characteristic frequency (CF) associated with the recording site (Russell and Murugasu 1997). Similarly, suppression of human otoacoustic emissions via efferent activation is more effective for stimulating frequencies slightly above and below the test probe frequency (Maison et al. 2000).

The advantage of psychoacoustical methods to infer the efferent effect is that they can be used in cases of both normal and mildly impaired hearing (unlike OAEs which can be eliminated by a mild hearing loss). Psychoacoustical studies suggest the efferent effect appears to decrease as the precursor frequency is set higher or lower in frequency than the subsequently presented masker (Bacon and Viemeister 1985; Bacon and Moore 1986). The present study uses a psychoacoustical forward-masking technique [fixed-duration masking curve (FDMC) method (Yasin et al. 2013a, b, 2014)] in which a precursor sound is presented to elicit the efferent response. The FDMC method avoids the confounds of previous forward-masking methods used to measure the efferent effect by using a combined duration of the masker-plus-signal stimulus of $25 \mathrm{~ms}$, which is within the efferent onset delay. Hence, the representation of the signal should be unaffected by efferent activity elicited by the masker. The effect of efferent activation on cochlear gain can then be separately studied by presenting a precursor sound (to activate the efferent system) prior to the onset of the combined FDMC masker-signal stimulus. The present study used the FDMC method to estimate the frequency range of efferent-mediated cochlear gain reduction in humans.

\section{Method}

\subsection{Listeners}

Three normal-hearing listeners participated (L1 (author), L2 and L3). All listeners had absolute thresholds better than $20 \mathrm{~dB}$ HL for sound frequencies between 0.25 
and $8 \mathrm{kHz}$ (ANSI 1996) and were practised in related psychoacoustical experiments. Listeners undertook between 4 and $10 \mathrm{~h}$ of training on subsets of the stimuli used for the main experiment. L2 and L3 were paid $£ 6 / \mathrm{h}$ for participation.

\subsection{Stimuli}

The signal was a 4-kHz sinusoid and the sinusoidal masker was either on-frequency (4 kHz) or off-frequency $(1.8 \mathrm{kHz})$; both signal and masker always began in sine phase (Yasin et al. 2013a, b, 2014). The signal had a total duration of 6-ms (3ms onset and offset ramps, 0-ms steady-state). Absolute thresholds for this signal, presented to the left ear, were 18.2, 20.1 and 23.5 dB SPL for listeners L1, L2 and L3. The masker had a total duration of $19 \mathrm{~ms}$ (2-ms onset and offset ramps, 15-ms steady-state). The frequency range of the efferent effect on cochlear gain was studied by presenting a bandlimited precursor sound centred at different frequencies prior to the onset of the combined FDMC masker-signal stimulus (see Fig. 1). The ipsilateral precursor, when present, was a 160-ms (5-ms onset and offset ramps, 150-ms steady-state), 200-Hz-wide (brickwall filtered) noiseband presented at $60 \mathrm{~dB}$ SPL. The precursor was presented at centre frequencies of 2.5, 3.0, 3.5, 3.75, 4.0, 4.25, $4.5,5.0$ or $5.5 \mathrm{kHz}$ at a precursor offset-masker onset silent interval of $10 \mathrm{~ms}$. A silent interval of $10 \mathrm{~ms}$ was chosen to reduce potential confusion effects when the precursor frequency was close to the signal frequency. Stimuli were presented via the left channel of a pair of Sennheiser HD 600 headphones.

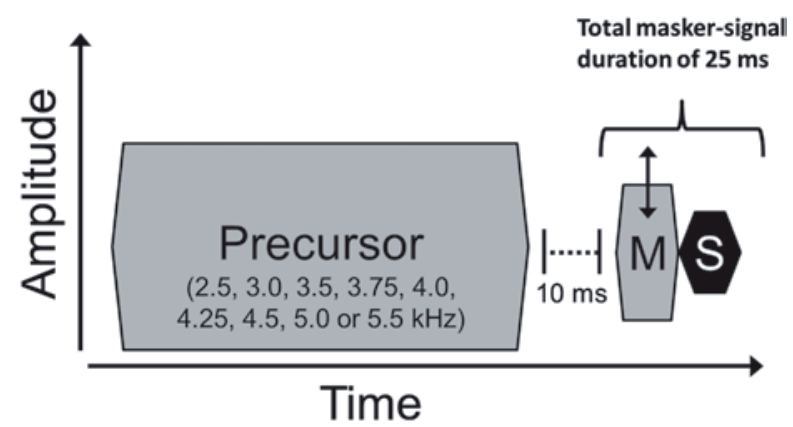

Fig. 1 Schematic of the stimuli used in phase 2 of the study. Masker (M) level at threshold for the signal (S) was measured using the FDMC method. Off-frequency or on-frequency maskerplus-signal total duration was $25 \mathrm{~ms}$ and masker-signal temporal interval was $0 \mathrm{~ms}$. A precursor was presented prior to the combined masker-signal stimulus at frequencies of 2.5, 3.0, 3.5, 3.75, $4.0,4.25,4.5,5.0$ or $5.5 \mathrm{kHz}$ at a level of $60 \mathrm{~dB}$ SPL. The silent temporal interval between precursor offset and masker onset was $10 \mathrm{~ms}$. Double-headed arrow indicates that the masker level was adaptively varied in each stimulus trial 


\subsection{Procedure}

The experiment consisted of two phases (Yasin et al. 2014). In phase 1, for each listener, signal level at threshold was measured per precursor frequency in the presence of a precursor and absence of any tonal masker, to take the forward masking of the precursor into account. In phase 2, the signal level was set at $15 \mathrm{~dB}$ SL (based on phase 1 results), a tonal masker was presented as well as the precursor, and masker level at threshold was measured for each precursor frequency and masker frequency. Phase 1 and phase 2 thresholds were also measured for a no-precursor condition. Thresholds were measured using a two-interval, two-alternative forced choice adaptive tracking procedure using a 2-down 1-up rule (phase 1), or a using a 2-up 1-down rule (phase 2) (Levitt 1971). Trial-by-trial feedback was provided. Per block of trials, the initial adaptive track step size was $5 \mathrm{~dB}$, which reduced to $2 \mathrm{~dB}$ after four reversals. Threshold was obtained by averaging stimulus levels for the next eight reversals, but the block was rerun if the standard deviation was greater than $6 \mathrm{~dB}$, or the nominal masker level reached $108 \mathrm{~dB}$ SPL or higher (due to soundcard output clipping). Listeners ran in $2 \mathrm{~h}$ sessions, taking breaks as needed. Condition order was randomized within sessions. Reported listener threshold values for phase 2 are the mean of 3-6 separate threshold estimates.

\section{Results}

The mean data obtained in the presence of a precursor are shown in Fig. 3. Masker levels at threshold obtained using a 1.8-kHz masker range from about 60 to $80 \mathrm{~dB}$ SPL, and remain roughly constant within this range as precursor frequency is increased from 2.5 to $5.5 \mathrm{kHz}$. Variability in data from listener L3 accounts for most of the dip seen in this data series. Masker levels at threshold obtained using a 4-kHz masker range from about 25 to $45 \mathrm{~dB}$ SPL, with the greatest masker level at threshold (about $45 \mathrm{~dB}$ SPL) associated with the presence of a precursor with a frequency close to that of the signal. Comparing masker levels at threshold for on- and offfrequency maskers in the presence of a precursor (elicits efferent activation) with masker levels obtained in the absence of precursor (absence of efferent activation), it can be seen that the greatest change in masker level at threshold (of about $20 \mathrm{~dB}$ ) occurs when there is an on-frequency masker, rather than an off-frequency masker, and this change is greatest when the precursor frequency is the same as, or just below, the $4-\mathrm{kHz}$ signal.

An estimate of inferred basilar-membrane gain can be obtained from the data as the difference between on- and off-frequency masker level values. The mean gain estimated in the absence of a precursor is $41 \mathrm{~dB}$. The estimated gain (as difference between on- and off-frequency masker levels) in the presence of a precursor of different frequencies is shown in Fig. 3. Maximum gain estimates of about $40 \mathrm{~dB}$ indicate little effect of any efferent-mediated cochlear gain reduction, and are asso- 


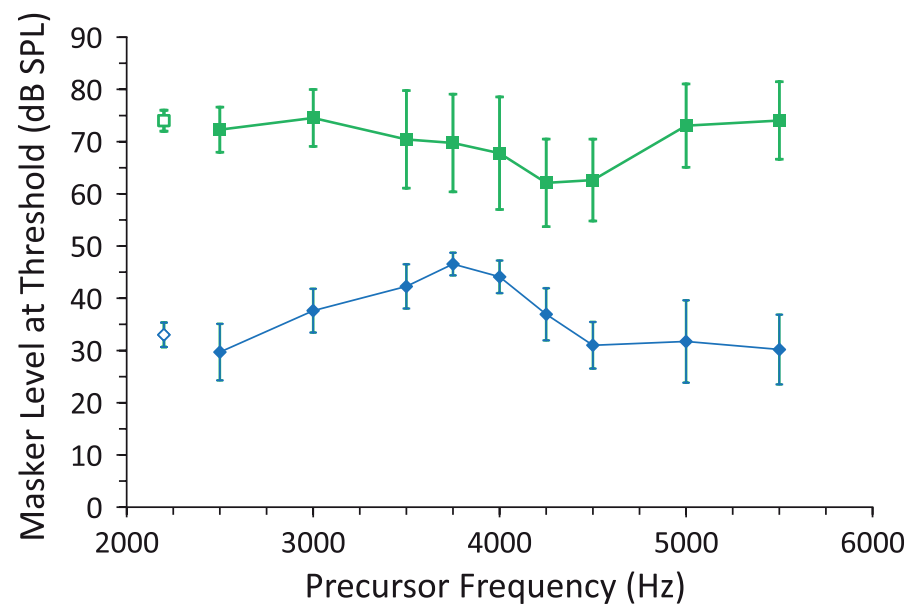

Fig. 2 Mean masker level at threshold (across three listeners) as a function of precursor frequency for on-frequency maskers ( $4 \mathrm{kHz}$, lower series) or off-frequency maskers $(1.8 \mathrm{kHz}$, upper series). Open symbols at left show masker level at threshold in the absence of a precursor. Error bars show \pm 1 standard error.

ciated with precursor frequencies well above and below that of the signal frequency of $4 \mathrm{kHz}$. Minimum gain estimates of about $20 \mathrm{~dB}$ indicate maximal effect of efferent-mediated cochlear gain reduction, and are associated with precursor frequencies close to that of signal frequency of $4 \mathrm{kHz}$. The estimated $10 \mathrm{~dB}$ bandwidth of the efferent-effect filter is $1300 \mathrm{~Hz}\left(\mathrm{Q}_{10}\right.$ of 3.1).

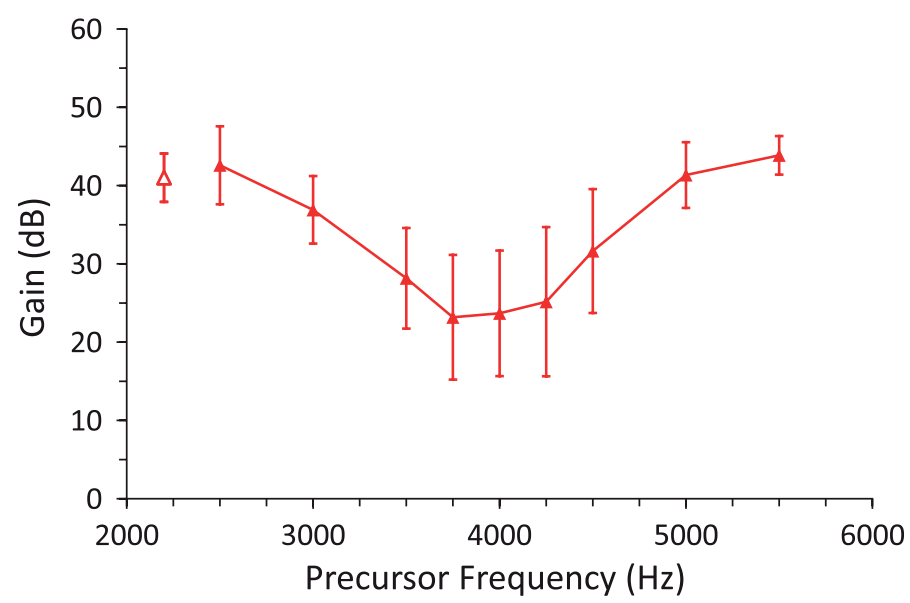

Fig. 3 Mean gain estimates (across three listeners) as a function of precursor frequency. Gain is calculated as the difference between masker levels at threshold obtained for on-frequency $(4-\mathrm{kHz})$ and off-frequency (1.8-kHz) maskers (Fig. 2). Open symbol at left shows mean gain value in the absence of a precursor. Error bars show \pm 1 standard error. 


\section{Discussion}

The FDMC method was used to obtain an estimate of the efferent effect in the absence (without a precursor) and presence (with a precursor presented at different frequencies) of efferent activation to investigate the frequency specificity of the efferent effect on cochlear gain. There was minimum cochlear gain reduction via efferent-activation when the precursor frequency was well removed from that of the signal frequency of 4-kHz, and maximal cochlear gain reduction (about $20 \mathrm{~dB}$ ) when the precursor frequency was the same as, or close to, that of the signal. The results suggest that the efferent effect extends for precursors up to about $0.5-0.7$ octaves above and below the signal frequency. The frequency range of the efferent effect found in the present study is similar to that observed with the measurement of otoacoustic emissions in humans, using simultaneous or contralateral elicitors. The tuning of the efferent effect can extend $0.5-2$ octaves above and below the frequency range of interest (spontaneous OAEs) or probe frequency (stimulus-frequency OAEs), as measured using simultaneous ipsilateral/contralateral tones (Lilaonitkul and Guinan 2009; Zhao and Dhar 2012). In most cases the tone/narrowband noise eliciting the efferent effect has maximal effect above a presentation level of $60 \mathrm{~dB}$ SPL, and in some cases the efferent effect has been shown to be more pronounced if the elicitor/precursor sound is about $0.5-1$ octave below the probe frequency (e.g., Mott et al. 1989; Harrison and Burns 1993). However, the present study does not appear to show such a distinct asymmetry in the tuning of the efferent effect.

Overall, direct comparisons of gain estimates between OAE- and psychophysical-based measures of efferent activation are problematic, even if measuring SFOAEs with elicitors (analogous to a precursor in psychophysical studies) mainly due to constraints in stimulus design. However, once the effects of OAE stimulus constraints such as the use of a broadband elicitor (presented contralaterally to elicit the greatest efferent response), use of an ongoing long-duration probe-tone stimulus (required for pre- and post-elicitor measurement of SFOAEs), and the possibility of two-tone cochlear suppressive effects with ipsilateral elicitor presentation are taken into account, the reduction in SFOAEs with an elicitor (e.g., Guinan et al. 2003) show gain reduction trends that may be in some cases comparable to those found in the present study. The present findings suggest that the $10 \mathrm{~dB}$ bandwidth of the efferent-effect filter at $4000 \mathrm{~Hz}$ is about $1300 \mathrm{~Hz}\left(\mathrm{Q}_{10}\right.$ of 3.1).

\section{Conclusions}

1. The FDMC method can be used to provide a measure of the frequency tuning of the efferent effect in humans using narrowband ipsilateral precursors.

2. Cochlear gain reduction is greatest for precursors with frequencies close to that of the signal, and least for precursors with frequencies well removed from the signal frequency. 
3. The tuning of the efferent effect filter ( $0.5-0.7$ octaves above and below the signal frequency) is within the range obtained in humans using OAEs (Lilaonitkul and Guinan 2009; Zhao and Dhar 2012).

4. The 10-dB bandwidth of the efferent-effect filter centred at $4000 \mathrm{~Hz}$ is about $1300 \mathrm{~Hz}\left(\mathrm{Q}_{10}\right.$ of 3.1).

Acknowledgements The research was supported by an EPSRC grant EP/H022732/1 and an International Project grant awarded by Action on Hearing Loss.

Open Access This chapter is distributed under the terms of the Creative Commons AttributionNoncommercial 2.5 License (http://creativecommons.org/licenses/by-nc/2.5/) which permits any noncommercial use, distribution, and reproduction in any medium, provided the original author(s) and source are credited.

The images or other third party material in this chapter are included in the work's Creative Commons license, unless indicated otherwise in the credit line; if such material is not included in the work's Creative Commons license and the respective action is not permitted by statutory regulation, users will need to obtain permission from the license holder to duplicate, adapt or reproduce the material.

\section{References}

ANSI (1996) ANSI S3.6-1996 Specification for audiometers. American National Standards Institute, New York

Backus BC, Guinan JJ Jr (2006) Time-course of the human medial olivocochlear reflex. J Acoust Soc Am 119:2889-2904

Bacon SP, Moore BCJ (1986) Temporal effects in simultaneous pure-tone masking: effects of signal frequency, masker/signal frequency ratio, and masker level. Hear Res 23:257-266

Bacon SP, Viemeister NF (1985) The temporal course of simultaneous tone-on-tone masking. J Acoust Soc Am 78:1231-1235

Guinan JJ Jr, Backus BC, Lilaonitkul W, Aharonson V (2003) Medial olivocochlear efferent reflex in humans: otoacoustic emission (OAE) measurement issues and the advantages of stimulus frequency OAEs. J Assoc Res Otolaryngol 4:521-540

Guinan JJ Jr (2006) Olivocochlear efferents: anatomy, physiology, function, and the measurement of efferent effects in humans. Ear Hear 27:589-607

Guinan JJ Jr (2010) Cochlear efferent innervation and function. Curr Opin Otolaryngol Head Neck Surg 18:447-453

Harrison WA, Burns EM (1993) Effects of contralateral acoustic stimulation on spontaneous otoacoustic emissions. J Acoust Soc Am 94:2649-2658

Huffman R, Henson OW (1990) The descending auditory pathway and acousticomotor systems: connections with the inferior colliculus. Brain Res Rev 15:295-323

James AL, Mount RJ, Harrison RV (2002) Contralateral suppression of DPOAE measured in real time. Clin Otolaryngol 27:106-112

Levitt H (1971) Transformed up-down methods in psychoacoustics. J Acoust Soc Am 49:467-477

Liberman MC (1988) Response properties of cochlear efferent neurons: monaural vs. binaural stimulation and the effects of noise. J Neurophysiol 60:1779-1798

Lilaonitkul W, Guinan JJ (2009) Human medial olivocochlear reflex: effects as functions of contralateral, ipsilateral, and bilateral elicitor bandwidths. J Assoc Res Otolaryngol 10:459-470

Maison S, Micheyl C, Andeol G, Gallego S, Collet L (2000) Activation of medial olivocochlear efferent system in humans: influence of stimulus bandwidth. Hear Res 140:111-125 
Mott JB, Norton SJ, Neely ST, Warr B (1989) Changes in spontaneous otoacoustic emissions produced by acoustic stimulation of the contralateral ear. Hear Res 38:229-242

Murugasu E, Russell IJ (1996) The effect of efferent stimulation on basilar membrane displacement in the basal turn of the guinea pig cochlea. J Neurosci 16:325-332

Russell IJ, Murugasu E (1997) Efferent inhibition suppresses basilar membrane responses to near characteristic frequency tones of moderate to high intensities. J Acoust Soc Am 102:1734-1738

Yasin I, Drga V, Plack CJ (2013a) Estimating peripheral gain and compression using fixed-duration masking curves. J Acoust Soc Am 133:4145-4155

Yasin I, Drga V, Plack CJ (2013b) Improved psychophysical methods to estimate peripheral gain and compression. In: Moore BCJ, Patterson RD, Winter IM, Carlyon RP, Gockel HE (eds) Basic aspects of hearing: physiology and perception. Springer-Verlag, Heidelberg, pp 39-46

Yasin I, Drga V, Plack CJ (2014) Effect of human auditory efferent feedback on cochlear gain and compression. J Neurosci 34:15319-15326

Zhao W, Dhar S (2012) Frequency tuning of the contralateral medial olivocochlear reflex in humans. J Neurophysiol 108:25-30 